Mario Luis Garcia de Figueiredo

\title{
IDENTIFICAÇÃO DE FLAVIVIRUS INFECTANDO \\ CULICÍDEOS DE 1999 a 2007 \\ NO BRASIL
}

Tese apresentada ao Instituto de Ciências

Biomédicas da Universidade de São

Paulo, para obtenção do Titulo de

Doutorado em Ciências (Microbiologia).

Área de concentração: Microbiologia

Orientador: Edison Luiz Durigon

São Paulo 


\section{RESUMO}

Figueiredo MLG. Identificação de flavivirus infectando culicídeos de 1999 a 2007 no Brasil , [ Tese (Doutorado)]. São Paulo. Departamento de Microbiologia , Universidade de São Paulo; 2010.

Introdução: Arbovírus são vírus transmitidos por artrópodos, pertencendo, principalmente, aos gêneros Flavivirus (Flaviviridae), Alphavirus (Togaviridae) e Orthobunyavirus (Bunyavirus). Os Flavivirus, em sua maioria, são associados a zoonoses, causando doenças humanas febrís, febres hemorrágicas e encefalites. Inclusive, causam epidemias que são sério problema de saúde pública. Este estudo mostra uma pesquisa de Flavivirus em culicídeos, de diferentes regiões do país, utilizando uma técnica para identificação viral por RT-PCR com primers Flavivirusespecíficos e uma Multiplex-nested-PCR com primers espécie-específicos.

Métodos: Culicídeos foram capturados, quantificados, identificados, agrupados em lotes por espécie e congelados. No laboratório, os animais foram macerados e tiveram o RNA extraído. Estes extratos foram submetidos a RT-PCR gênero-específica e à Multiplex-nested-PCR, para detecção e identificação dos vírus a nível de espécie.

Resultado: De 3317 culicídios adultos e 571 larvas coletados em 4 diferentes regiões do Brasil, Sul, Sudeste, Norte e Nordeste, fez-se 246 lotes de mosquitos e desses foi possível obter amplicon sugestivo de Flavivirus em 16 (6,5\%). Em 3 lotes contendo larvas de Aedes albopictus obteve-se amplicon sugestivo de vírus do dengue tipo 3 . Também, em 13 lotes contendo Haemagogus leucocelaenus, Aedes aegypti e Aedes albopictus foi possível obter amplicons sugestivos de vírus do dengue tipos 1 e 2 . Dos amplicons obtidos, 4 tiveram nucleotídios seqüenciados o que permitiu confirmar a presença dos vírus do dengue tipo 3 e Cacipacoré.

Conclusão: $O$ trabalho permitiu concluir que: a metodologia de RT-PCR para Flavivirus seguida de Multiplex-nested-PCR espécie-específica foi adequada para detecção e identificação destes vírus em culicídios; amplificaram-se genomas de Flavivirus em 6,5\% dos lotes de culicídios estudados; vírus do dengue tipo 1 e tipo 2 foram encontrados infectando Aedes aegypti de Santos em 1999, Manaus em 20052006 e Foz do Iguaçu; vírus do dengue tipos 2 e 3 foram encontrados em Aedes albopictus de Santos em 1999 e Manaus em 2005-2006, sugerindo que este mosquito participe na transmissão de dengue; vírus do dengue tipo 3 foi encontrado em larvas de Aedes albopictus mostrando transmissão vertical do vírus; vírus do dengue tipo 1 foi encontrado infectando Haemagogus sp. sugerindo existência de ciclo silvático deste vírus; Aedes aegypti do Amazonas estavam infectados com o vírus Cacipacoré.

Palavras-chave: arbovírus. Culicídeos. Flavivirus. vírus do dengue. Vírus Cacipacoré. 


\begin{abstract}
Figueiredo MLG. Identification of flavivirus infecting culicídeos of 1999 to 2007 in Brazil, [PHD. Thesis]. São Paulo. Departamento de Microbiologia, Universidade de São Paulo; 2010.

Introduction: Arbovirus are rodent-borne viruses mostly from Flavivirus (Flaviviridae), Alphavirus (Togaviridae) e Orthobunyavirus (Bunyavirus) genus. Flavivirus, are commonly zoonotic and can cause febrile illness, haemorrhagic fever and encephalitis. Flavivirus outbreaks occur in Brazil and are a major public health problem. We show here a research looking for Flavivirus infections in Culicidae by a RT-PCR using Flavivirus-especific primers and a Multiplex-nested-PCR using specie-specific primers for virus identification.

Methods: Culicidae were captured, quantified, identified, pooled based on the specie and frozzen. In the laboratory, the animals were crushed and had the RNA extracted. These extracts were tested by a Flavivirus genus-specific RT-PCR followed by a specie-specific Multiplex-nested-PCR.

Results: From 3317 captured adult Culicidae and 571 collected larvae in 4 different regions of Brazil, 246 pools were obtained and from these, Flavivirus indicative amplicons were obtained in 16 (6.5\%). Amplicons of dengue type 3 were obtained from 3 pools of Aedes albopictus larvae. It was also possible to obtain indicative amplicons of dengue types 1 and 2 in 13 pools of Haemagogus leucocelaenus, Aedes aegypti and Aedes albopictus. Besides, 4 amplicons had the nucleotides sequenced, confirming the mosquito infection by dengue type 3 and Cacipacoré viruses.

Conclusion: The technique combining a Flavivirus genus-specific RT-PCR followed by a specie-specific Multiplex-nested-PCR was suitable for detection of these viruses in the mosquitoes; Flavivirus infecting Culicidae were detected in $6.5 \%$ of the analyzed mosquito pools; dengue virus type 1 and type 2 were found infecting Aedes aegypti from Santos (1999), Manaus (2005-2006) and Foz do Iguaçu cities; dengue type 2 virus was found in Aedes albopictus from Santos city (1999) and Manaus city (2005-2006), suggesting that this mosquito could be participating on dengue transmition; dengue type 3 virus was found in Aedes albopictus larvae showing the vertical transmission of this virus; dengue type 1 virus was found infecting Haemagogus sp. what suggests on the existence of a sylvatic maintenance cycle of this virus; Aedes aegypti from Amazonas state were found infeted by Cacipacoré virus.
\end{abstract}

Key-words: arbovirus. Culicidae. Flavivirus. dengue vírus. Cacipacore virus. 


\section{Introdução}

\subsection{Os Arbovírus}

Os arbovírus tem seu nome originado da expressão em língua inglesa arthropod borne viruses, significando vírus transmitidos por artrópodos. Com este nome classifica-se vírus de diferentes famílias (Togaviridae, Flaviviridae, Bunyaviridae, Reoviridae, Rhabdoviridae) segundo um critério eminentemente epidemiológico (Brown, 1986). Estes vírus mantêm-se na natureza em ciclos complexos envolvendo um ou mais vertebrados-reservatório que podem ser seres humanos ou animais domésticos e vetores artrópodos que se infectam ao sugarem o vertebrado virêmico, passando a transmitir o microorganismo ao sugarem, posteriormente, outros animais. É importante ressaltar que a transmissão não é mecânica e ocorre após período de incubação necessário para que o patógeno acometa as glândulas salivares do vetor. Os artrópodos causadores de arboviroses incluem mosquitos, carrapatos, flebótomos, percevejos e possivelmente, pulgas (Beaty, et al, $1995)$.

O Brasil é o país em que o maior número de arbovírus foi descrito, principalmente na região Amazônica, onde ocorrem condições climáticas ideais à criação de uma diversidade enorme de vetores alados (mosquitos) e animais silvestres. Ali, isolou-se mais de 200 arbovírus sendo que, aproximadamente, 30 foram relacionados a doença humana. Dentre os arbovírus que ocorrem no Brasil destacam-se os Flavivirus, tanto por produzirem o maior número de infecções e doenças humanas, como pela gravidade destas doenças produzindo febres hemorrágicas e meningoencefalites (Rosa, et al, 1998). 


\subsection{Os Flavivirus}

Os Flavivirus apresentam formato esférico, com aproximadamente $50 \mathrm{~nm}$ de diâmetro, são envelopados e com projeções na superfície (espículas). O genoma é constituído por RNA de fita simples, linear, de polaridade positiva, contendo no terminal 5' 7-metilguanosina (cap), no entanto, o terminal 3' não é poliadenilado, o que distingue a família Flaviviridae dentre os vírus RNA de polaridade positiva. Cada terminal apresenta regiões NTR, sendo que a parte proximal 3'NTR é considerada bastante heterogênea entre os vários Flavivirus. O genoma inclui dez genes que codificam três proteínas estruturais (proteínas do core-C, da membrana-M e a glicoproteína de superfície-E) e sete proteínas não estruturais (NS1, ns2a, ns2b, ns3, ns4a, ns4b e ns5), das quais a NS5 apresenta seqüências nucleotídicas mais conservadas entre as várias espécies do gênero (Lindenbach, et al, 2007).

Existem mais de 70 espécies de Flavivirus, muitas das quais causadoras de doenças humanas as quais podem se manifestar de forma distinta, desde quadros febrís agudos com, artralgias, cefaléia e mialgias a formas mais graves como febres hemorrágicas, hepatite e encefalite. No Brasil, já foram descritas doze espécies de Flavivirus (Figueiredo, 2000), (Figueiredo, 2008). Os Flavivirus brasileiros podem ser filogenéticamente agrupados em três ramos principais: o da febre amarela, o dos vírus do dengue com sub-ramos para os tipos 1, 2 e 4, e o ramo que inclui o vírus da Encefalite japonesa, que não ocorre no país, juntamente com os vírus brasileiros da encefalite de Saint Louis, Cacipacoré, Iguape, Rocio, Ilhéus e Bussuquara (Baleotti, et al, 2003). Estes são vírus transmitidos por mosquitos Culex, são zoonoses de aves e quando infectam o homem podem causar encefalite.

O vírus da febre amarela (YFV) é causador de grave hepatite com febre hemorrágica em cerca de 10\% dos indivíduos que com ele se infectam (Vasconcelos, 2003). YFV, introduzido nas Américas a partir da África, adaptou-se a um novo 
ciclo silvestre, americano, envolvendo primatas e mosquitos Haemagogos da copa das árvores (Soper, 1936). Trata-se de uma zoonose silvestre que circula em praticamente todo o país produzindo casos humanos. Após 1999, epizootias por YFV em primatas e casos humanos começaram a ocorrer na região Sudeste. Surtos no estado de Minas Gerais, próximos a Belo Horizonte, ocorreram em 2001, 2004 e 2005 e em Brasília, neste início de 2009. Os surtos costumam ser precedidos por epizootias com mortandade de primatas. Nos últimos 2 anos, casos de febre amarela vem ocorrendo no Estado do Rio Grande do Sul e no de São Paulo (Ministério da Saúde do Brasil, Informe sobre febre amarela, 2009). Nos surtos, vem sendo acometidos ecoturistas, pescadores, trabalhadores agrícolas e motoristas de caminhão (Ministério da Saúde do Brasil, Informe sobre febre amarela, 2006). Próximos a grandes cidades infestadas por Aedes aegypti, estes surtos trazem preocupação quanto à reurbanização da febre amarela. Sabe-se que o ciclo urbano de YFV não tem sido relatado no Brasil desde 1942 (Franco, 1969; Ministério da Saúde, Informe sobre febre amarela, 2006). Entretanto, transmissão urbana de YFV teria ocorrido próxima à fronteira brasileira, em Santa Cruz de la Sierra, Bolívia, há 10 anos e no Paraguai em 2007 (Vander Stuyf, 1999). Para o controle da febre amarela, dispõe-se de uma importante arma, a vacina de vírus atenuado 17DD. Esta vacina tem sido usada no Brasil há 65 anos e mais de 212 milhões de doses já foram aplicadas (Benchimol, 2001).

O vírus Rocio (ROCV) foi isolado pela primeira vez em 1975, de um indivíduo com encefalite fatal durante epidemia ocorrida no Vale do Ribeira, litoral sul do estado de São Paulo, e que durou de 1973 a 1980 (Lopes, et al, 1978). Foram aproximadamente 1000 casos de encefalite notificados, com uma letalidade de $10 \%$ e entre os sobreviventes, cerca de $20 \%$ apresentaram seqüelas motoras ou de equilíbrio (Iversson, et al, 1997). Com base em fontes de isolamento viral, acredita-se que 
ROCV seja mantido em ciclo envolvendo aves silvestres, inclusive migratórias e tendo mosquitos Psorophora e Aedes como vetores (Iversson, et al., 1997). A emergência deste novo Flavivirus, foi surpreendente e seu desaparecimento no Vale do Ribeira, não concluiu sua ameaça. Indivíduos com anticorpos neutralizantes para ROCV foram encontrados na região Sudeste e Nordeste do Brasil nas décadas de 80 e 90 (Figueiredo, et al, 1986),(Straatmann, et al, 2007). Ainda, em 2004, 2 pássaros capturados no estado do Rio Grande do Sul apresentavam anticorpos para ROCV (Araujo, Ministério da Saúde do Brasil, comunicação pessoal, 2005). Assim, é possível supor que este vírus causador de grave encefalite epidêmica, circule em regiões distintas de Brasil com uma ameaça permanente de reemergência causando epidemias.

O vírus da encefalite de Saint Louis (SLEV) encontra-se extensamente distribuído nas Americas, do Canadá à Argentina. No Brasil, SLEV foi primeiramente isolado em 1960, de um pool de Sabethes belisarioi capturados na estrada BelémBrasília. Posteriormente, determinou-se que SLEV possui pássaros selvagens, primatas, preguiças, tamanduás e marsupiais como reservatórios e Culex declarator e coronator como vetores (Vogel, et al, 2005). Provavelmente, aves migratórias dispersariam o vírus pelo continente americano. Na cidade paulista de São Pedro, em 2004, SLEV foi isolado de um paciente com doença febril aguda (Rocco, et al, 2005). Em 2006, durante grande epidemia de dengue que ocorria na cidade de São José do Rio Preto, encontrou-se em sangue e ou liqüor de 6 pacientes, com diagnóstico de meningoencefalite, febre do dengue ou dengue hemorrágico, o genoma de SLEV (Mondini, et al, 2007). Este foi o primeiro surto de SLEV detectado no Brasil, estando este mascarado por uma epidemia de dengue. Assim, sabe-se que SLEV circula causando epidemias no estado de São Paulo. Entretanto, é desconhecido o ciclo arbovírico mantenedor do vírus o que impede qualquer medida de controle. 
WNV é o exemplo clássico de um vírus emergente. Típico causador de epidemias no Velho Mundo, especialmente na África e Oriente Médio, WNV foi descoberto, em 1999, causando um surto de meningoencefalite, pela primeira vez no Continente Americano, na cidade de Nova York (Nash, et al, 2001). O vírus, rapidamente, se espalhou por toda a América do Norte tornando-se um sério problema de saúde pública além de causar epizootias em cavalos. Até 2007, nos Estados Unidos, notificaram-se 27379 casos desta virose, com 8885 casos de encefalite, 1060 fatais (CDC, 2007). De qualquer forma, é notável a forma como WNV se adaptou rapidamente a um novo ciclo mantenedor, com mosquitos e aves americanas (West Nile Vírus Activity Reports, 2005) WNV tem se disseminado rumo sul em aves migratórias de longa distância. Foram detectados cavalos com anticorpos neutralizantes na Colômbia em 2005 (Mattar, et al, 2005). Em 2006, WNV foi isolado do cérebro de dois cavalos com encefalite na Argentina (Morales, et al, 2006). Assim, o surgimento de WNV no Brasil é altamente provável, inclusive porque muitas aves migratórias, que são reservatórios de $\mathrm{WNV}$, migram para o país e também, mosquitos Culex e aves como o pardal (Passer domesticus), conhecidos reservatórios virais, são abundantes nas cidades brasileiras (West Nile Virus Acivity Report, 2005). Buscando por aves silvestres infectadas por WNV no Brasil, em 2004, examinaram-se 5000 pássaros selvagens de diferentes regiões e todos foram seronegativos (Araujo, Ministério da Saúde do Brasil, comunicação pessoal, 2005). Para detectar a introdução de WNV no país seria importante estudar eqüinos, aves silvestres e mosquitos.

Os vírus do dengue (DENV) causam a principal arbovirose em nível mundial e são da maior importância para o nosso país (Fonseca, Figueiredo, 2006). Aproximadamente 2,5 bilhões de indivíduos, em cerca de 100 países, estão em risco de contrair a infecção e estima-se que ocorram anualmente cerca de 100 milhões de 
casos de dengue clássico e mais de 500 mil casos de dengue hemorrágico, com letalidade de até 10\% (Halstead, 2007). Nas últimas décadas têm-se observado um incremento significativo na atividade epidêmica, expansão da distribuição geográfica, transmissão contínua de vários tipos e emergência de dengue hemorrágico em áreas onde a doença não era prevalente. Um dos eventos mais importantes dos últimos anos tem sido o aumento do número de casos da forma hemorrágica nas Américas e o aumento dos casos com manifestações clínicas não-usuais do dengue. (Holmes, 1998).

No Brasil, desde a introdução do vírus do tipo 1 (DENV-1), em 1986, no Rio de Janeiro, ocasião em que ocorreu epidemia explosiva de doença febril aguda com mais de 3 milhões de infecções, a situação desta arbovirose vem continuamente se agravando e isto, conseqüentemente, representa um fracasso para nosso sistema de saúde (Figueiredo, et al, 1990). Em 1987, DENV-1 espalhou-se pela costa nordeste do Brasil causando gigantescas epidemias. Em 1991, o vírus do dengue tipo 2 (DENV-2) inicia grande surto no Rio de Janeiro e pela primeira vez, começam a ser observados casos da forma hemorrágica. Estes casos eram principalmente associados a infecções secundárias, ou seja, indivíduos que tiveram DENV-1 e posteriormente DENV-2. DENV-2 espalhou-se por todo o Brasil produzindo epidemias de doença febril aguda e dezenas de casos de dengue hemorrágico, muitos fatais, em Fortaleza, Maceió, Natal e Recife. Desde então o dengue torna-se endêmico com os 2 tipos circulando simultaneamente ou alternando-se em epidemias sucessivas por todas as regiões do Brasil, em cidades infestadas por Aedes aegypti. Em 1997, o Ministério da Saúde tentou implantar um programa ambicioso de erradicação do mosquito Aedes aegypti e que fracassou completamente. A partir de 1998, as epidemias de dengue agravaram-se assustadoramente no Brasil. São centenas de milhares de casos notificados todo ano e casos de dengue hemorrágico surgindo de forma crescente (Figueiredo, 2003), 
(Fonseca, 2006). A partir de 2001, o dengue tipo 3 (DENV-3) foi introduzido no Rio de Janeiro e em 2002, explodiu gigantesca epidemia no Brasil. Mais de 800000 casos foram notificados em 2002 e centenas de casos de dengue hemorrágico ocorreram com cerca de 100 óbitos (Ministério da Saúde, Informes sobre dengue, 2003 e 2007). Em 2005 e 2006, todo o Brasil viveu grande epidemia de DENV-3 com centenas de milhares de casos de febre do dengue, milhares de casos de dengue hemorrágico e centenas de óbitos (Ministério da Saúde, Informes sobre dengue, 2003 e 2007). Em 2007, ocorreu grande epidemia de DENV-3 em Matogrosso do Sul. Até a $18^{\mathrm{a}}$ semana de 2007 foram notificados 247.121 casos no país, o que representa um aumento de cerca de 29,58\% quando comparado com o mesmo período de 2006. Em 2008 ocorreu enorme surto por dengue tipo 2 no Rio de Janeiro (Ministério da Saúde, Informe sobre Dengue, 2008). Finalmente, divulgou-se a ocorrência do dengue tipo 4 (DENV-4) em Manaus (Figueiredo, et al, 2008). O número de casos confirmados acumulados no Brasil de 1981 a 2009 ultrapassou 5 milhões. Em relação ao dengue hemorrágico, a situação é de extrema preocupação devido ao aumento impressionante no número de c sos nos últimos anos (PAHO, 2007).

\subsection{Os mosquitos}

Atualmente, são conhecidos cerca de três e meio milhares de espécies de dípteros nematoceros (mosquitos e pernilongos) da família Culicidae, que estão distribuídas por todo o mundo, excetuando, apenas, regiões permanentemente congeladas como a do continente Antártico. Mosquitos e pernilongos atuam como vetores na transmissão de uma enorme quantidade de microorganismos. Dentre estes microorganismos destacam-se vírus, protozoários e helmintos.

A infecção dos culicídeos por vírus tem início na luz do trato digestivo ao ingerirem o plasma ou células sanguíneas infectadas. A replicação viral nas células do 
trato digestivo médio costuma ser imediata acompanhando a digestão dos alimentos. Quando esta replicação não ocorre diz-se que há uma barreira entérica à replicação viral o que significa incompetência vetorial do artrópodo para aquele microorganismo (Nuttall, et al, 1994). Estudos mostram que a forma mais eficiente de infecção dos dípteros nematoceros com arbovirus é a co-alimentação destes em um vertebrado juntamente com outro culicideo infectado (Nuttall, et al, 1994). Os culicídeos mantêm o arbovírus na natureza participando de seus ciclos habituais vetor-reservatório e também, transmitindo-os de forma transovariana à prole, mantendo infectivas várias gerações destes animais, bem como transmitindo o vírus para seus estádios posteriores de desenvolvimento. Supõe-se que a transmissão transovariana é fenômeno que ocorre em pequena quantidade dentre as tribos dos culicídeos na natureza. Experimentos em laboratório sobre transmissão transovariana dos 4 tipos de vírus do dengue, por Aedes aegypti e Aedes albopictus observando que o fenômeno era freqüente e mantinha-se por mais de duas gerações (Gubler, Rosen, 1983), (Rosen, et al, 1983).

A transmissão viral por artrópodos dá-se, mais frequentemente, pela saliva que é secretada durante a alimentação destes animais. As glândulas salivares dos culicídeos tem grandes dimensões e estes possuem na saliva substancias com atividade anti-hemostática, vasodilatadora, anti-inflamatória e imunossupressora. Sob efeito da saliva, o vírus penetra em tecidos do vertebrado com capacidade reativa reduzida à infecção (Nuttall, et al, 1994).

Associado à adaptabilidade destes vetores a diversos hospedeiros incluindo o homem, animais domésticos e, ainda, animais silvestres em domesticação, mantêm-se ou mesmo aumenta o nicho ecológico onde ocorrem arboviroses. Também, tem sido observado que nem sempre a relação dos arbovírus com artrópodos é benéfica a ambos. Há casos em que arbovírus podem matar seus vetores mosquitos adultos. O 
virus ao infectar o mosquito pode causar distúrbios fisiológicos de digestão e salivação (Lambrechts, 2009), danos a tecidos durante a replicação viral (Vaidyanathan, Scott, 2006) e levar a espécie a baixas taxas de natalidade (Lambrechts, 2009).

Finalmente, cabe lembrar que, tão importante quanto as pesquisas emergenciais durante os surtos das doenças por arbovírus, são os estudos fora do contexto epidêmico. Em geral, com base nestes estudos é que podem-se definir os nichos ecológicos de Flavivirus e tomar medidas preventivas evitando, desta forma, a morte de muitas pessoas.

\subsection{Reação em cadeia da polimerase e sequenciamento nucleotídico}

Um método diagnóstico de infecções por Flavivirus que possui grande sensibilidade e praticidade é a reação em cadeia pela polimerase (Mullis, et al, 1986) que deve ser precedida de transcrição reversa no caso dos vírus de RNA, transformando seus genomas em DNAc, trata-se da RT-PCR. A transcrição reversa, que utiliza transcriptase reversa oriunda de retrovirus, possibilita amplificar, in vitro, fragmento do RNA viral. Utiliza-se na PCR enzima termoestável, em presença de oligonucleotideos e primers (iniciadores), que determinam a região à ser amplificada. Em nosso meio, a RT-PCR vem sendo utilizada para detecção genômica diagnóstica de vários vírus de RNA (De Paula, et al, 2002), (Moreli, et al, 2002),( Bronzoni, 2004).

O seqüenciamento nucleotídico de produtos amplificados pela RT-PCR, denominados amplicons, permite analisar comparativamente as seqüências obtidas com as de vários Flavivirus previamente conhecidos (Batista, et al, 2001), ( Baleotti, et al, 2003), ( Kuno, et al, 1998).

Nos anos 70, (Maxam, et al, 1977) desenvolveram os métodos químicos pioneiros para sequenciar fragmentos de DNA. Nesta mesma década, Sangers e cols, 
1978, divulgaram uma versão melhorada do método, utilizando finalizadores dideoxinucleotideos. Estes finalizadores 2', 3'dideoxinucleotídeos trifosfatos (ddNTPS), não possuem o radical 3'hidroxil que permite a continuação da cadeia de ácidos nucléicos e portanto, quando inseridos pela polimerase, interrompem a cadeia de DNA. Finalizadores dideoxinucleotideos C, G, T e A marcados com isótopos radioativos ou, mais recentemente, com substâncias fluorescentes, podem ser utilizados em uma PCR que em seguida tem as seqüências interrompidas separadas, segundo o tamanho, por eletroforese, sendo seu dideoxinucleotideo fluorescente terminal detectado. Em suma, as seqüências são montadas em computador acoplado ao equipamento leitor para que seja obtida a real seqüência do produto em teste. A um aparelho contendo este conjunto de equipamentos acoplados denominamos seqüenciador de nucleotídios. Para a reação de seqüenciamento, amplicons podem ser seqüenciados diretamente após processo de purificação ou clonados em vetor plasmidial antes do procedimento (Batista, 2001), (Baleotti, 2003).

\subsection{Justificativa para o trabalho}

Considerando que existem poucos estudos sobre níveis de infecção por Flavivirus em seres humanos, animais domésticos, silvestres e vetores:

- É importante conhecer a diversidade genética destes vírus e de seus vetores.

- É dever da Universidade, no caso o Instituto de Ciências Biomédicas da Universidade de São Paulo, estudar os potenciais vetores e Flavivirus causadores de enfermidades em nosso Estado e no Brasil.

Assim, idealizou-se este estudo para conhecer a infecção por arbovírus do gênero Flavivirus, entre os Culicídeos de diferentes regiões do Brasil. Desta forma, seria possível conhecer Flavivirus pouco comuns que ocorrem em distintas regiões do país, além das tradicionais flaviviroses causadoras de doença humana, como a do dengue e 


\section{Conclusões}

- A metodologia de detecção gênero-específica de Flavivirus por RT-PCR, seguida de multiplex-nested-PCR espécie-específica mostrou-se adequada ao estudo com culicídeos.

- Amplificaram-se genomas de Flavivirus em $16(6 \%)$ dos 264 lotes de culicídios estudados.

- Vírus do dengue tipo 1 e tipo 2 foram encontrados infectando Aedes aegypti oriundos de, Santos em 1999, Manaus em 2005-2006 e Foz do Iguaçu, locais onde ocorreram epidemias por estes vírus.

- Vírus do dengue tipo 2 e tipo 3 foram encontrados infectando Aedes albopictus oriundos de Santos em 1999 e Manaus em 2005-2006, sugerindo que este mosquito possa participar na transmissão de dengue no Brasil.

- Vírus do dengue tipo 3 foi encontrado infectando larvas de Aedes albopictus oriundas de Santos em 1999, mostrando a ocorrência, em natureza, de transmissão vertical deste vírus, provavelmente, transovariana.

- Vírus do dengue tipo 1 foi encontrado infectando Haemagogus sp. oriundos da Bahia, sugerindo uma possível existência de ciclo silvático deste vírus no Brasil.

- Aedes aegypti do Amazonas foram observados infectados com o vírus Cacipacoré, causador de doenca febril aguda humana e cuja transmissão por este vetor poderia causar grandes epidemias urbanas. 


\section{Referências bibliográficas:}

American Committee on Arthropod-borne Viruses. International catalogue of arboviruses including certain other viruses of vertebrates. 3th ed., San Antonio, Texas: The American Society of Tropical Medicine and Hygiene, 1985.

Altschul, SF, Gish, W, Miller, W, Myers, EW, Lipman, DJ. Basic local alignment search tool. J Mol Biol., 1990, 215, 403-410.

Amarilla, AA, Almeida, FT, Jorge, DM, Alfonso, HL, Castro-Jorge, LA, Nogueira, NA, Figueiredo, LTM, Aquino, VH. Genomic diversity of the E Protein of Dengue Type 3 Virus., Virol J., 2009.

Anderson, JF, Andreadis, TG, Main, AJ, Kiline, DL. Prevalence of west nile vírus in tree canopy-inhabiting Culex pipiens and associeted mosquitoes. Am J Trop Med Hyg., 2004, 7, 112-119.

Baleotti, FG, Moreli, ML, Figueiredo, LTM. Brazilian Flavivirus phylogeny based on NS5. Mem Inst Oswaldo Cruz., 2003, 98, 379-382.

Batista, WC, Kashima, S, Marques, AC, Figueiredo, LTM. Phylogenetic analysis of Brazilian Flavivirus using nucleotide sequences of parts of NS5 gene and 3' noncoding regions. Virus Research., 2001, 75, 35-42.

Beaty, BJ, Calisher, CH, Shope, RE. Arboviruses. Lennette, E.H.; Lennete, D. A.; Lennete, E.T.; (Editors). Diagnostic procedures for viral, rickettsial, and chlamydial infections, Seventh ed., Washington, American Public Health Association., 1995, 189-212.

Benchimol, JL. Febre amarela: a doença e a vacina, uma história inacabada. Rio de Janeiro, Editora Fiocruz., 2001, 469p.

Bharadwa, M, Botten, J, Torrez- Martinez, N, Hjelle, B. Rio Mamore Vírus: genetic characterization of a newly recognized hantavirus of the pygmy rice rat, Oligoryzomys microtis, from Bolívia. Am J Trop Med Hyg., 1997, 57, 368-374.

Brown, F. The classification and nomenclature of viruses : summary of meetings of the International Committee on Taxonomy of Viruses in Sendai, September Intervirol., 1986, 25, 141-143. 
Bronzoni, RVM, Nogueira, RMR, Nunes, M, Figueiredo, LTM. Detection and identification of Brazilian alphaviruses and flaviviruses by multiplex RT-PCR, J Clin Microbiol., 2005, 43, 696-702.

Bronzoni, RVM, Moreli, ML, Cruz, ACR, Figueiredo, LTM. Multiplex-nested-PCR for Brazilian Alphavirus diagnosis. Trans Roy Soc Med Trop Hyg., 2004, 98, 456461.

CDC Division of Vector Borne Infectious Diseases. West Nile Virus: statistics, surveillance and control, 2007.

Chao, DY, Davis, BS, Chang, GJ. Development of a multiplex real-time reverse transcriptase PCR assays for detecting eight medically important flaviviruses in mosquitoes. J Clin Microbiol., 2007, 45, 584-589.

Consoli, RAGB, Oliveira, RL. Principais Mosquitos de Importância Sanitária no Brasil Rio de Janeiro. Fundação Oswaldo Cruz, Rio de Janeiro., 1994, 225p.

Dégallier, N, Travassos da Rosa, APA, Hervé, JP, Travassos da Rosa, JFS, Vasconcelos, PFC, Silva, CJM, Barros, VLRS, Dias, LB, Travassos da Rosa, ES, Rodrigues, SG. A comparative study of yellow fever in Africa and South America. J Braz Ass Adv Science (Ciência e Cultura)., 1982, 44, 143-151.

Dégallier, N, Teixeira, JMS, Soares, SS, Pereira, RD, Pinto, SCF, Chaib, AJM, Vasconcelos, PFC, Oliveira, E. Aedes albopictus may not be vector of dengue virus in human epidemics in Brazil. Rev Saúde Pública., 2003, 37, 386-387.

De Paula, SO, Pires Neto, RJ, Corrêa, JA, Assumpção, SR, Costa, ML, Lima, DM, Fonseca, BA. The use of reverse transcription-polymerase chain reaction (RT-PCR) for the rapid detection and identification of dengue virus in an endemic region: a validation study.Trans R Soc Trop Med Hyg., 2002, 96, 266-269.

Eads, RB. Recovery of Aedes albopictus from used tires shipped to united States ports. Mosq News., 1972, 32, 113-114.

Figueiredo, LTM, Abe Owa, M, Carlucci, R H, Oliveira, L. Estudo sobre diagnostico laboratorial e sintomas do dengue, durante epidemia ocorrida em Ribeirão Preto, SP, Brasil. Rev Inst Med Trop S Paulo., 1992, 34, 121-130,.

Figueiredo, LTM, Owa, MA, Carlucci, RH, Mello, NV, Fabbro, A L, Capuano, DM, Santili, MB. Dengue Serologic Survey in Ribeirão Preto, SP, Brazil. PAHO Bull., 1995, 29, 59-69. 
Figueiredo, LTM, Simões, MC, Cavalcante, SMB. Dengue serologic survey of school children in Rio de Janeiro, Brazil, 1986 and 1987. PAHO Bull., 1990, 24, 217-225.

Figueiredo, LTM, Travassos da Rosa, APA, Fiorillo, AM. Níveis de anticorpos para arbovírus em indivíduos da Região de Ribeirão Preto, SP (Brasil). Rev Saúde pública, S Paulo., 1986, 20, 204-211.

Figueiredo, LTM. The Brazilian Flaviviruses. Microbes and Infection., 2000, 2, 1643 1649.

Figueiredo, LTM. Dengue in Brazil: Past, present and future perspective. Dengue Bullettin (WHO)., 2003, 27, 25-33.

Figueiredo, RM, Naveca, FG, Bastos, MS, Melo, MN, Viana, SS, Mourão, MP, Costa, CA, Farias, IP. Dengue virus type 4, Manaus, Brazil. Emerg. Infect. Dis., 2008, 14, 667-669.

Fonseca, BAL, Figueiredo, LTM. Dengue. In: Roberto Focaccia, (ed.). Tratado de Infectologia. São Paulo, Atheneu., 2006, 343-356.

Forattini, OP. Identificação de Aedes ( Stegomyia) albopictus ( Skuse) no Brasil. Rev. Saúde Publica., 1986, 20, 244-245.

Forattini, OP. Culicidologia Médica. Editora Universidade de São Paulo, EDUSP, 2, , 2002, 860p.

Franco, O. História da Febre Amarela no Brasil. Ministério Saúde, SUCAM., Rio de Janeiro, 1969.

Fulop, L, Barrett, ADT, Phillpotts, R, Martin, K, Leslie, D, Titball, RW. Rapid identification of flaviviruses based conserved NS5 gene sequences. J Virol Meth., 1993, 44, 179-188.

Gubler, DJ, Rosen, L. Variation among geographic strains of Aedes albopictus in susceptibilityto infection with dengue viruses. Am J Trop Med Hyg., 1976, 25, 318325.

Hall T BioEdit: a user-friendly biological sequence alignment editor and analysis program for Windows 95/98/NT Nucl Acids Symp Ser., 1999, 41, 95-98. 
Halstead, SB. Dengue. Lancet., 2007, 370, 1644-1652.

Henriques, DA. Caracterização molecular de arbovírus isolados na fauna díptera nematócera do Estado de Rondônia (Amazônia Ocidental Brasileira). Tese de Doutorado em Microbiologia, São Paulo (Brasil): Instituto de Ciências Biomédicas da Universidade de São Paulo, 2007.

Holmes, EC. Molecular epidemiology and evolution of emerging infectious diseases. British Med Bull., 1998, 54, 533-543.

Huang, C, Morse, D, Slater, B, Amand, M, Tobim, Smith, P, Dupuis, M, Hull, R Frrera, RR, Rosem, B, Grady, L. Multiple-year expirience in the diagnosis of viral central nervus system infection whith a panel of polymerase chain reaction assay for detection of 11 virus. CID., 2004, 39, 630-635.

Huang, C, Slater, B, Campbell, W, Howard, J, White, D. Detection of arboviral RNA directly from mosquito homgenates by reverse- transcrition- Polymerase Chain Reaction J Virol Meth., 2001, 94, 121-128.

Instituto Brasileiro Geografia e Estatística, IBGE, Dados estatísticos do Brasil, 2006. Acesso 12/12/2006.

Iversson, LB, Tiriba, AC. Encefalite por arbovírus Rocio. In: Veronesi R, Focaccia R (eds) Tratado de Infectologia, Atheneu, São Paulo, 1997, 233-239.

Kamer, G, Argos, P. Primary structure comparison of RNA-dependent polymerases from plant, animal and bacterial vírus. Nucleic Acids Research, 1984, 12, 7269-7282.

Kramer, LD, Wolfe, TM, Green, EN, Chiles, R, Fallah, H, Fang, Y, Reisen, WK. Detection of encephalitis vírus in mosquitoes ( Diptera: Culicidae) and avian tisues. J Med Entomol., 2002, 39, 2, 312-323.

Kumar, S, Nei, M, Dudley, J, and Tamura, K. A biologist-centric software ., for evolutionary analysis of DNA and protein sequences B R I E F INGS IN B IOINF OR MAT I C S, MEGA, 2008, 9, O4, 299-306.

Kuno, G, Chang, GJ, Tsuchiya, KR, Karabatsos, N, Cropp, CB. Phylogeny of the genus Flavivirus. J Virol., 1998, 72, 73-83.

Lambrechts, L, Scott, TW. Mode of transmission and the evolution of arbovirus virulence in mosquito vectors. Proc Biol Sci., 2009, 7, 1369-1378. 
Laemmert, HW, and Hughes, TP. The vírus of ilhéus encephalitis. Isolation, serological specifity and tranmission, J Immunol., 1947, 55, 61-67.

Lindenbach, BD, Thiel, HJ, Rice CM. Flaviviridae: the viruses and their replication. In: Knipe DM, Howley PM (eds), Fields Virology, $5^{\text {th }}$ ed, Lippincot Williams \& Wilkins, Philadelphia, 2007, 1101-1151.

Lopes, OS, Coimbra, TLM, Sacchetta, LA, Calisher, CH. Emergence of a new arbovirus disease in Brazil. 1. Isolation and characterization of the etiologic agent, Rocio virus. Am J Epidemiol., 1978, 107, 444-449.

Marcondes, CB, Santos-Neto, LG, Lozovei, AL. Ecology of phlebotomine sandflies (Diptera, Psychodidae) in Brazilian Atlantic Forest. Rev Soc Bras Med Trop, 2001, 34, 255-260.

Mattar, S, Edwards, E, Laguado, J, Gonzalez, M, Alvarez, J, Komar, N. West Nile vírus antibodies in Colombian horses. Emerg Infect Dis., 2005, 11, 1497-1498.

Maxam, AM, Tizard, R, Skryabin, KG, Gilbert, W. Promotor region for yeast 5S ribosomal RNA.Nature, 1977, 16, 643-645.

Medeiros, DB, Nunes, MR, Vasconcelos, PF, Chang, GJ, Kuno, G. Complete genome characterization of Rocio virus (Flavivirus: Flaviviridae), a Brazilian flavivirus isolated from a fatal case of encephalitis during an epidemic in Sao Paulo state. J Gen Virol., 2007, 88, 2237-2246.

Ministério da Saúde do Brasil. Informes sobre dengue, 2003, 2007 e 2008.

Ministério da Saúde do Brasil. Informes sobre febre amarela, 2006 e 2009.

Mitchell CJ. Vector competence of North and South American strains of Aedes albopictus for certain arboviruses. J Amer Mosq contr Ass., 1991, 7, 446-451.

Moncayo AC, Edman, JD. Toward the incrimination of epidemic vectors of eastern equine encephalomyelitis virus in Massachusetts: abundance of mosquito populations at epidemic foci. J Amer Mosq contr Ass., 1999, 15, 479-492.

Mondini, A, Lázaro, E, Cardeal, ILS, Nunes, SH, Moreira, CC, Rahal, P, Figueiredo, LTM, Bronzoni, RVM, Chiaravalloti Neto, F, Nogueira, ML. Two flavivirus, Saint Louis encephalitis (SLEV) and dengue type 3 (DENV3), causing simultaneous outbreaks in Brazil. Emerg Infect Dis., 2007, 13, 176-178. 
Morales, MA, Barrandeguy, M, Fabbri, C, Garcia, JB, Vissani, A, Trono, K, Gutierrez, G, Pigretti, S, Menchaca, H, Garrido, N, Taylor, N, Fernandez, F, Levis, S.; Enría, D. West Nile virus isolation from equines in Argentina. Emerg Infect Dis., 2006, 12, 1559-1561.

Moreli, ML, Aquino, VH, Cecília, ARC, Cruz, Figueiredo, LTM. Diagnosis of Oropouche virus infection by RT-Nested-PCR; J Med Virol., 2002, 66, 139-142.

Mullis, K, Faloona, F, Scharf, S, Saiki, R, Horn, G, Erlich, H. Specific enzimatic amplification of DNA in vitro: the polymerase chain reaction. Cold Spring Harb. Symp Quant Biol., 1986, 51, 263-273.

Nash, D, Mostashari, F, Fine, A, Miller, J, O’Leary, D, Murray, K. The outbreak of West Nile virus infection in the New York City area in 1999. New Engl J Med., 2001, 344, 1807-1814.

Nogueira, RMR, Miagostovich, MP, Filipis, AMP, Pereira, MAS, Schatzmayr, HG. Dengue virus type 3 in Rio de Janeiro, Brazil. Mem Inst Oswaldo Cruz, 2001, 96, 925-926.

Nuttall, PA, Jones, LD, Labuda, M, Kaufman, WR. Adaptations of arboviruses to ticks. J Med Entomol., 1994, 31, 1-9.

O’Guinn, M, Lee, JS, Koding, JP, Fernandez, R, Carbajal, Fernandez, R, Carbajal, F. Field detection of eastern equine encephalitis vírus in the amazon basin region of peu using reverse transcription- polymerase chain reaction adapted for field identification of arthropod borne pathogens. Am J Trop Med Hyg., 2004, 70, 164-171.

PAHO. Dengue in the Americas, 2007.

Pinheiro, FP. Situação das arboviroses na região amazônica. International Simposium on Tropical Arboviruses and Haemorrhagic Fevers, Belém, 1980. Academia Brasileira de Ciências, Rio de Janeiro, 1982, 27-48.

Pinto, CS, Confalonieri, UE, Mascarenhas, BM. Ecology of Haemagogus sp. and Sabethes sp. (Diptera: Culicidae) in relation to the microclimates of the Caxiuanã National Forest, Pará, Brazil. Mem Inst Oswaldo Cruz, 2009, 104, 592-598.

Posada, D, Crandall, KA. Performance of methods for detecting recombination from DNA sequences: computer simulations. Proc Natl Acad Sci U.S.A., 2001, 98, 35713762 . 
Roberts DR, Peyton EL, Pinheiro, FP, Balderrama, F, Vargas, R. Asociación de vectores de arbovirus con galerias arboreas y el medio domestico en el sureste de Bolivia. Bol Ofic sanit Panamer, 1985, 98, 417-30.

Rocco, IM, Santos, CLS, Bisordi, I, Petrella, SMCM, Pereira, LE, Souza, RP, Coimbra,TLM, Bessa, TAF, Oshiro, FM, Lima, LBQ, Cerroni, MP, Marti, AT, Barbosa, VM, Katz, G, Suzuki, A. St. Louis encephalitis virus: first isolation from a human in São Paulo State, Brazil. Rev Inst Med trop., S. Paulo, 2005, 47, 281-285.

Rosa, JFST, Rosa, APAT, Vasconcelos, PFC, Pinheiro, FP, Rodrigues, SG, Travassos da Rosa, ES, Dias, LB, Cruz, ACR. Arboviruses isolated in the Evandro Chagas Institute, including some described for the first time in the Brazilian Amazon region, their known hosts, and their pathology for man. In: Rosa, APAT,Vasconcelos, PFC, Rosa, JFST (eds); An overview of arbovirology in Brazil and neighbouring countries. Instituto Evandro Chagas, Belém, 1998, 19-31.

Rosen, L, Shroyer, DA, Tesh, RB, Freier, JE, Lien, JC. Transovarial Transmission of Dengue Viruses By Mosquitoes: Ae albopictus and Ae aegypti. Am J Trop Med Hyg, 1983, 32, 1108-1119.

Sambrook J, Russell D, Russell D.W. Molecular Cloning, A Laboratory Manual, Cold Spring Harbor, CSHL Press, 2000, 1.

Samuel, PP, Tyagi, BK. Diagnostic methods for detection e isolation of dangue vírus for vector mosquitoes. Indian J Med Res., 2006, 123, 615-628.

Sanger, F, Coulson, AR, Friedmann, T, Air, GM, Barrell BG, Brown, NL, Fiddes, JC, Hutchison, CA, Slocombe, PM, Smith, M. The nucleotide sequence of bacteriophage phiX174. J Mol Biol., 1978, 125, 225-246.

Scaramozzino, N, Crance, J, Jouan, A, Debriel, DA, Stoll, F, Garin, D. Comparison of flavivuses universal primer pairs and development of a rapid, highly sensitive heminested RT-PCR assay for detection of flaviviruses targeted to a conserved region of the NS5 gene sequences. J Clin Microbiol., 2001, 39, 1922-1927.

Serufo, JC, de Oca, HM, Tavares, VA, Souza, AM, Jamal, MC, Lemos, JR, Oliveira, MA, Nogueira, RM, Schatzmayr, HG. Isolation of dengue type 1 from larvae of Ae albopictus in campos Alto city, State of Minas Gerais, Brazil. Mem Inst Oswaldo Cruz., 1993, 88, 503-504.

Shannon RC, Methods for collecting and feeding mosquitoes in jungle yellow fever studies. AM J. Trop Med Hyg., 1939,19, 131-138. 
Silva, CCA. Activatio of prophenoloxidase and removal of Bacillus subtilis from the hemolymph of Acheta domesticus (L)(Orthoptera: Gryllidae). Neotrop Entomol., 31, 487-491.

Soper, FL. Febre amarela silvestre. Novo aspecto epidemiológico da doença. Rev Hyg Saúde Púb., 1936, 10, 107-44.

Sprenger, D, Wuithiranyagool, T. The discovery and distribuition of Aedes albopictus in Harris County, Texas. J Amer Mosq Control Assoc., 1986, 2, 217-219.

Straatmann, A, Santos-Torres, S, Vasconcelos, PF, Rosa, APT, Rodrigues, SG, Tavares-Neto, J. Serological evidence of the circulation of the Rocio arbovirus (Flaviviridae) in Bahia. Rev Soc Bras Med trop., 1997, 30, 511-515.

Swofford, D., PAUP*: phylogenetic analysis using parsimony (*and other methods). In Version 4.0b10a Sunderland, Mass: Sin-auer Associates; 1998.

Tamura, K, Dudley, J, Nei, M Kumar, S.; MEGA4: Molecular evolutionary genetics analysis (MEGA) software version 4.0 Mol Biol Evol, 2007, 24, 1596-1599.

Thoisy, B, Lacoste, V, Germain, A.; Muñoz-Jordán, J.; Colón, C.; Mauffrey, J.F.; Delaval, M.; Catzeflis, F.; Kazanji, M.; Matheus, S.; Dussart, P.; Morvan, J.; Setién, A.A.; Deparis, X., Lavergne1, A.; Dengue Infection in Neotropical Forest Mammals., 2009 Vector-borne ad Zoonotic Disease, 9, 2, CMary Ann Liebert.

Travassos da Rosa, JFS, Travassos da Rosa, APA, Vasconcelos, P.F.C.; Rodrigues, S.G.; Travassos da Rosa, E.S.; Dias L.B.; Cruzi, A.C.R.; Arboviruses isolated in the Evandro Chagas Institute, including some described for the first time in the Brazilian Amazon region, their known hosts, and their pathology for man, in: Travassos da Rosa, A.P.A.; Vasconcelos, P.F.C.; Travassos da Rosa, J.F.S. (Eds.).; An Overview of Arbovirology on Brazil and Neighboring Countries, Instituto Evandro Chagas, Belém, 1998, 19-31.

Thompson, JD, Higgins, DG, and Gibson, TJ. CLUSTAL W: improving the sensitivity of progressive multiple sequence alignment through sequence weighting, position specific gap penalties and weight matrix choice, Nucleic Acids Research, 1994.

Vaidyanathan, R, Scott, TW. Seasonal variation in susceptibility to West Nile virus infection in Culex pipiens pipiens (L.) (Diptera: Culicidae) from San Joaquin County, 
California. J Vector Ecol., 2006, 31, 423-425.

Van der Stuyft, P, Gianella, A, Pinard, M, Cespedes, J, Lora, J, Peredo, C, Pelegrino, JL, Vorndam, V, Boelaert, M. Urbanisation of yellow fever in Santa Cruz, Bolívia. Lancet, 1999, 353, 1558-1562.

Vasconcelos, PFC, Menezes, DB, Melo, LP. A large epidemic of dengue fever with dengue hemorrhagic cases in Ceará State, Brazil. Rev Inst Med trop., S. Paulo, 1995, $37,253-255$.

Vasconcelos, PF, Rosa, AP, Rodrigues, SG, Rosa, ES, Monteiro, HA, Cruz, AC, Barros, VL, Souza, MR, Rosa, JF. Yellow fever in Pará State, Amazon region of Brazil, 1998-1999: entomologic and epidemiologic findings. Emerg Infect Dis., 2001, 7, 565-569.

Vasconcelos, PFC, Travassos da Rosa, APA, Dégallier, N, Travassos da Rosa JFS, Pinheiro, FP. Clinical and ecoepidemiological situation of human arboviruses in Brazilian Amazonia. J. Braz. Ass. Advanc. Science (Ciência e Cultura)., 1992, 44, 117-124.

Vasconcelos PF, Yellow Fever. Rev Soc Bras Med Trop., 2003, 36, 275-293.

Vogel, P, Kell, WM Fritz, DL, Parker, MD Schoiepp, RJ.Early events in the pathogenesis of eastern equine encephalitis virus in mice. AM J Pathol., 2005, 166, 159-171.

West Nile Virus Activity - United States, January 1-December 1, 2005. MMWR., 2005,54, 1253-1256. 